\title{
Model results for the ionospheric lower transition height over mid-latitude
}

\author{
J. Lei ${ }^{1,2}$, L. Liu ${ }^{1}$, W. Wan ${ }^{1}$, and S.-R. Zhang ${ }^{3}$ \\ ${ }^{1}$ Institute of Geology and Geophysics, Chinese Academy of Sciences, Beijing 100029, China \\ ${ }^{2}$ Wuhan Ionospheric Observatory, Wuhan Institute of Physics and Mathematics, Chinese Academy of Sciences, Wuhan \\ 430071, China \\ ${ }^{3}$ Haystack Observatory, Massachusetts Institute of Technology, Westford, Massachusetts, USA
}

Received: 7 November 2003 - Revised: 25 February 2004 - Accepted: 8 March 2004 - Published: 14 June 2004

\begin{abstract}
Theoretical calculations of the ionospheric lower transition height (LTH), a level of equal $\mathrm{O}^{+}$and molecular ion densities, were performed and compared with empirical models by Zhang et al. (1996). This paper represents a substantial extension of the prior work by including the AE-C data of ion composition analysis and by detailed quantitative studies of the LTH simulation, and by creating a new LTH empirical model based on our simulations. Results show that: (1) the calculated LTH, in general, is lowest near 11-13 LT and reaches the diurnal maximum after midnight (about $01 \sim 02 \mathrm{LT}$ ). The local time asymmetry becomes more evident in summer, when the time of minimum shifts to 16 LT. (2) The simulated LTH presents a dominant, semiannual variation during nighttime, and a pronounced annual variation during daytime. (3) The simulated LTH increases with solar activity at night and decreases by day, while the standard IRI option has an opposite tendency at night in summer and equinox. Therefore, the day-night difference of simulated LTH significantly increases with solar activity. (4) Both daytime and nighttime LTHs, tend to increase with the increasing geomagnetic activity $A_{p}$ index, with a mean slope about $0.1455 \mathrm{~km}$ per $A_{p}$ unit. (5) The diurnal variation of LTH is found to be more than $20 \mathrm{~km}$, which is much larger than the seasonal variation under F107=100 and $A_{p}=10$. Thus, the diurnal and solar activity variations of LTH are more pronounced than its seasonal and magnetic activity variations.
\end{abstract}

Key words. Ionosphere (ion chemistry and composition; modeling and forecasting; middle-latitude ionosphere)

\section{Introduction}

The lower transition height (LTH) is an important parameter representing the level where the concentrations of atomic and molecular ions are equal. As is known, deriving the plasma parameters in the F1-region from the incoherent scatter radar

Correspondence to: J. Lei

(leijh@wipm.ac.cn)
(ISR) spectrum depends on the assumption of the ion composition profile (e.g. Pavlov and Buonsanto, 1998; Schlesier and Buonsanto, 1999; Pavlov et al., 1999). On the other hand, the lower transition height can be used as an anchor point for the empirical model of the ionospheric ion composition profile by the International Reference Ionosphere (IRI) (Bilitza, 1990a, 1991). Therefore, a better understanding of this characteristic height will be very helpful for the analysis of ISR data and will open up the possibility of improving the IRI ion composition representation.

Several studies have investigated the variation of the ion composition which is closely related to the LTH. Oliver (1975) studied the ion composition in the F1-region with rockets and satellites data, and developed an empirical formulation for the lower transition height (Bilitza, 1990a), which involved the zenith angle, seasonal, annual and semiannual variations, but did not include the solar flux and magnetic activity variations. Danilov and Yaichinikov (1985) constructed an ion composition model for IRI (Bilitza, 1990a) based on the rockets data, which yields, however, a quite small day-night difference of LTH (Zhang et al., 1996). Hoegy et al. (1991) compared ion compositions measured by a number of satellites with empirical/theoretical models and revealed some outstanding differences. Danilov and Simirnova (1995) produced a new ion composition model that updated the Danilov and Yaichinikov (1985) model and was used in the IRI2000 model (Bilitza, 2001). Also, the ion composition information can be deduced from ISR experiential data (Lathuillere and Pibaret, 1992; Cabrit and Kofman, 1996; Litvine et al., 1998), although the inversion analysis is mainly implemented for the EISCAT scatter radar and strongly depends on the data resolution and geophysical conditions. Because of spare observed data for the ion composition in the F1-region, theoretical models can help understand the variations in the ion composition parameters and fill the data gap. Zhang et al. (1996) compared the calculated LTH with IRI and Oliver's model, and obtained some meaningful results, while they did not carry out quantitative studies of this characteristic height. 

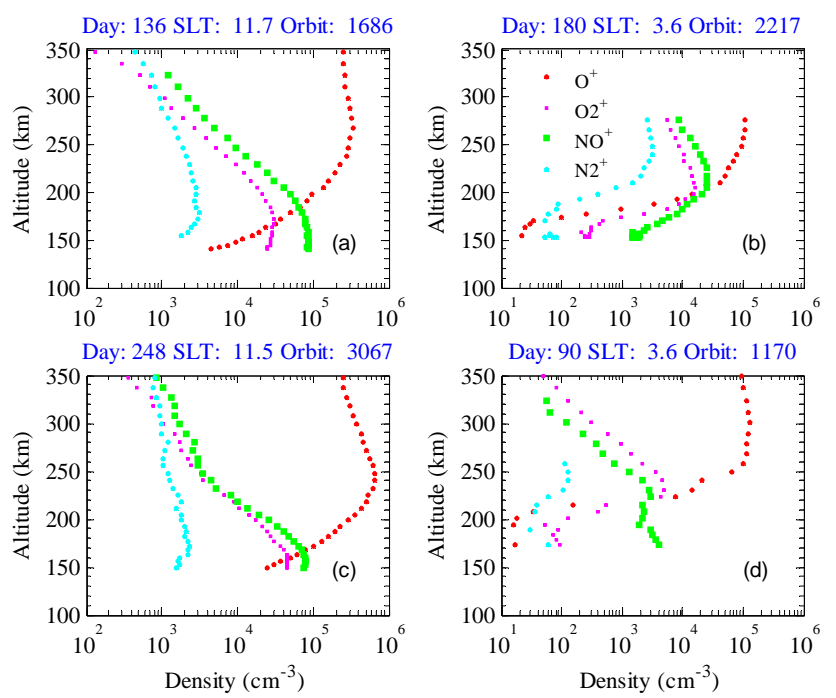

Fig. 1. Altitude profiles of ion composition obtained from Atmosphere Explorer-C.

The aim of this study is to investigate the diurnal, seasonal, annual and semiannual variations of LTH. We will focus on the quantitative variations of LTH with solar flux F107 and magnetic activity $A_{p}$ indices to extend the work of Zhang et al. (1996). Furthermore, an empirical model is developed to depict the variation in LTH at mid-latitude based on our calculations. First, we give a description of the ionospheric model in Sect. 2, and then in Sect. 3 present simulated results and also a comparison with LTH from the AE-C ion composition data. Finally, the discussions and summary are made.

\section{Ionospheric model}

A one-dimensional theoretical model has been developed for the mid-latitude ionosphere over the altitude range of 100 $600 \mathrm{~km}$. It solves the equations of mass continuity and motion for $\mathrm{O}^{+}$. Ion densities for $\mathrm{O}_{2}^{+}, \mathrm{NO}^{+}$, and $\mathrm{N}_{2}^{+}$are calculated under the assumption of photochemical equilibrium. The solar flux EUVAC model (Richards et al., 1994) is used to define the EUV flux, and the absorption and ionization cross sections are taken from Richards et al. (1994). Meanwhile, the scheme for calculating the secondary ionizations is taken from Titheridge (1996). The nighttime EUV fluxes are based on the work of Strobel et al. (1974), and the nighttime photoionization cross sections are obtained from Huba et al. (2000).

We include 21 chemical reactions for $\mathrm{O}^{+}\left({ }^{4} \mathrm{~S}\right), \mathrm{O}^{+}\left({ }^{2} \mathrm{D}\right)$, $\mathrm{O}^{+}\left({ }^{2} \mathrm{P}\right), \mathrm{O}_{2}^{+}, \mathrm{N}_{2}^{+}$, and $\mathrm{NO}^{+}$, which are listed in Table 1 . The scheme of chemical reactions is somewhat similar to the model of Pavlov and Foster (2001) and Pavlov (2003) in terms of the reaction rates for stable and meta-stable ions. As emphasized by Pavlov et al. (1999, and references therein), the vibrationally excited $\mathrm{N}_{2}$ and $\mathrm{O}_{2}$ have significant effects on the $\mathrm{O}^{+}$loss rate. The model includes the $\mathrm{O}^{+}\left({ }^{4} \mathrm{~S}\right)+\mathrm{N}_{2}(v)$
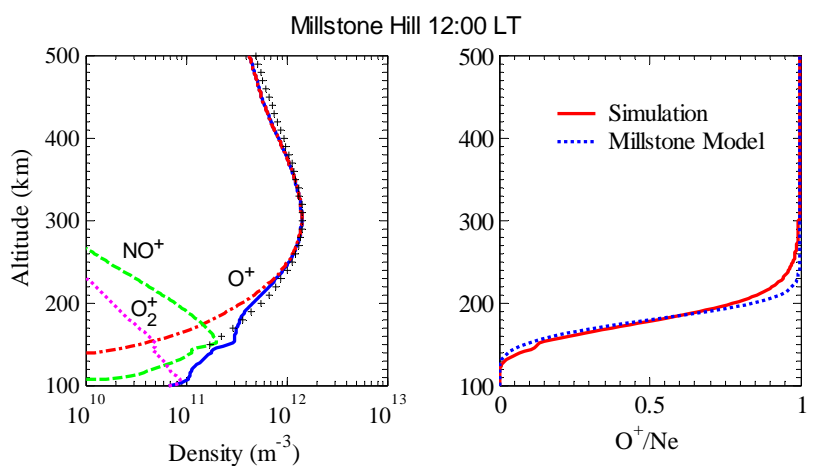

Fig. 2. Example of the comparison between the observed electron profile (symbol "+") and the model (solid line) on 27 September 2000 , and $\mathrm{O}^{+}, \mathrm{O}_{2}^{+}$, and $\mathrm{NO}^{+}$concentrations are also presented (left panel). In right panel, calculated $\mathrm{O}^{+} / \mathrm{Ne}$ are compared to the Millstone Hill standard ion-composition model.

reaction rate measured by Schmeltekopf et al. (1968), and the reaction rate constants for the first five vibrational levels are obtained from Pavlov et al. (1999) (see Table 1). The analytical approach for the solution of the steady-state vibrational quanta continuity equation is used to provide the vibrational temperature $T_{v i b}$, which can give the similar results for $N_{m} F_{2}$ and $h_{m} F_{2}$ to the full solution of the vibrational quanta continuity equation (Pavlov and Buonsanto, 1996). The rate coefficients of $\mathrm{O}^{+}\left({ }^{4} \mathrm{~S}\right)+\mathrm{O}_{2}(v)$ are given by Hierl et al. (1997) to include the effect of $\mathrm{O}_{2}(v)$.

The ion continuity equation for $\mathrm{O}^{+}$can be solved by an implicit, time-stepping numerical method with specified boundary and initial conditions. For the lower boundary at $100 \mathrm{~km}$, an assumption of photochemical equilibrium is adopted. The electron densities at the upper boundary and plasma temperatures between the boundaries are provided by a local ionospheric model (Holt et al., 2002), which was constructed from the incoherent scatter radar measurements made since 1976 over Millstone Hill. Neutral atmospheric parameters are taken from the NRLMSISE-00 model (Picone et al., 2002), and the NO density is calculated from an empirical model developed by Titheridge (1997). The HWM93 model (Hedin et al., 1996) is applied to specify neutral winds for our ionospheric model.

Model calculations were carried out for Millstone Hill $\left(42.6^{\circ} \mathrm{N}, 288.5^{\circ} \mathrm{E}\right)$ under a variety of solar geophysical conditions: day number of the year between 10 and 360 with an increment of 10, F107 index between 60 and 240 with an increment of 20, and $A_{p}$ values between 10 and 210 with an increment of 10 .

\section{Observations and model calculations}

The purpose of the AE-C mission was to investigate the thermosphere, with an emphasis on the energy transfer and processes that govern its state (http://nssdc.gsfc.nasa.gov/ ftphelper/). A lot of collected data can be used to study in 

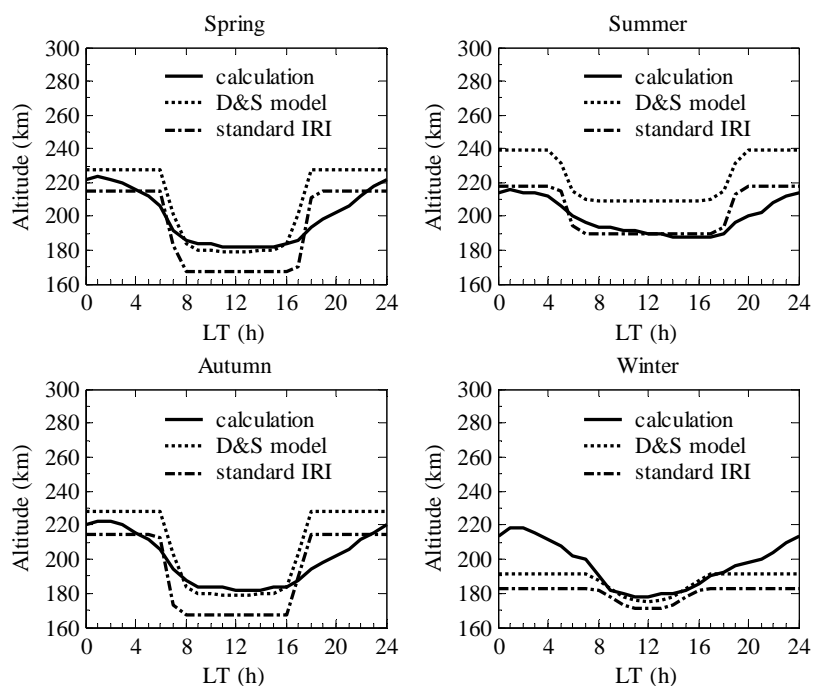

Fig. 3. Diurnal variation of the lower transition height as given by the simulated results, the standard IRI and D\&S model (Danilov and Simirnova, 1995) for four seasons under F107=100 and $A_{p}=10$.

great detail the ionosphere and thermosphere (upper atmosphere) and the coupling processes between them. The AE$\mathrm{C}$ satellite was initially injected into a highly elliptical orbit with an apogee near $4000 \mathrm{~km}$ and a perigee near $150 \mathrm{~km}$, with an inclination of $67^{\circ}$. For the first 12 months after its emission, its perigee was periodically lowered to $137 \mathrm{~km}$ while its apogee decayed rapidly. The orbit was changed to a circular orbit at about $300 \mathrm{~km}$ and was kept in this orbit mode from March 1975 to December 1976. The satellite was then raised to about $400 \mathrm{~km}$ and remained in a circular orbit at this height for the rest of its lifetime. Therefore, during the low perigee period, the ion density profiles at lower F-regional altitudes can be used to determine the lower transition height (LTH) for this study. We made use of individual ion density derived from the magnetic ion mass spectrometer (MIMS) (Hoffman et al., 1973). To give comparison with our model results, we limited the AE-C ion composition data to the latitude range of $20-60^{\circ}$, and assumed that the horizontal variation of ion density at middle latitudes can be negligible. Figure 1 shows the measured ion composition from the perigee to higher altitudes from 4 orbits. The molecular ions $\mathrm{O}_{2}^{+}$and $\mathrm{NO}^{+}$are the main constituents below the F1-region, while $\mathrm{O}^{+}$is the dominant species above this altitude in the F-region. The transition height from dominant molecular to atomic ions is higher during nighttime (Fig. 1b and d) than during daytime (Fig. 1a and c), and higher in summer (Fig. 1a and b) than in equinox (Fig. 1c and d).

Figure 2 shows the comparison of height profiles of the calculated electron density with the ISR observation, and the ion species on 27 September 2000 over Millstone Hill. The good agreement between the model and observed electron density validates our model results. The simulated ion composition shows good agreement with the observation in Fig. 1. The transition height is around $180 \mathrm{~km}$ during day-
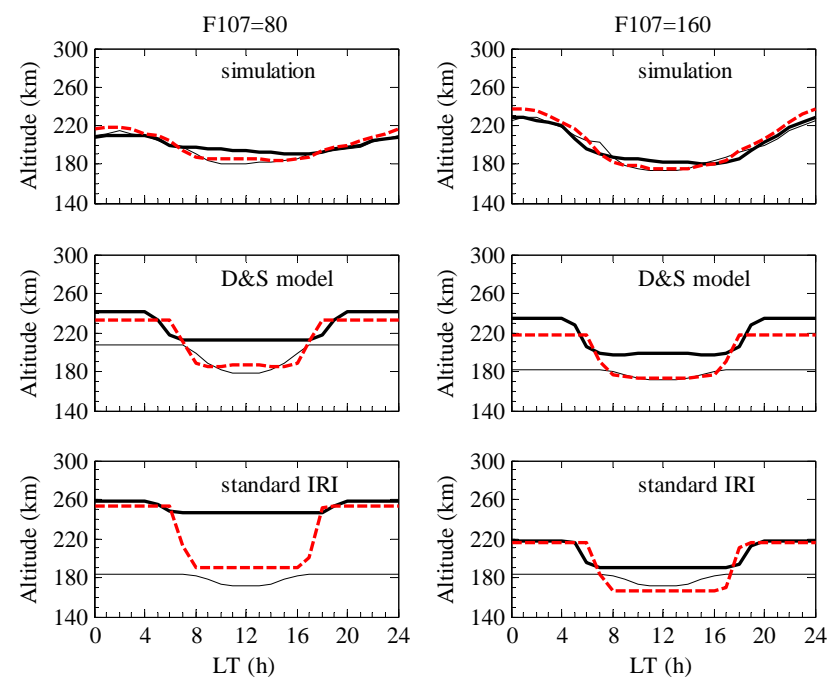

Fig. 4. Seasonal effect shown by the simulated LTH and the IRI model (standard IRI and D\&S model) at two solar activity levels: left panel for $F 107=80$, and right panel for F107=160. Heavy solid lines for summer, dash lines for equinox, and light solid lines for winter.

time, and rises to higher altitudes at night (see Figs. 3 and 4). The calculated $\mathrm{O}^{+} / \mathrm{Ne}$ ratio is very close to the standard Millstone Hill ion composition model on this quiet day, so no correction is needed to apply to the measured $\mathrm{Ne}(h)$, $T e(h)$ and $T i(h)$. However, under disturbed days, differences in $\mathrm{O}^{+} / \mathrm{Ne}$ ratio between the model results and the standard Millstone Hill ion composition model (Schlesier and Buonsanto, 1999; Pavlov et al., 1999) are likely to occur. As a result, the calculated ion compositions from ionospheric model may be used to correct the measured temperature and electron density by utilizing the multiplicative factors of Waldteufel (1971).

\subsection{Diurnal and seasonal variations}

Figure 3 shows the diurnal variations of the simulated LTH for four seasons against local time (LT) under F107=100 and $A_{p}=10$. The diurnal variation of LTH is, in general, similar to that of the peak density height $(h m \mathrm{~F} 2)$, lower during the day and higher by night. Table 2 shows characteristic values of the diurnal variation of LTH, which reaches its maximum at about 01-02 LT, and its minimum at 11-13 LT for all seasons except during summer, where the minimum value occurs at 16 LT in the afternoon. The diurnal variation shows an almost identical behavior in spring and autumn, so we will use the equinox case to represent its variations in these two seasons in the afterward discussion. The LTH shows the largest day-night difference in equinox seasons and the least in summer. This behavior is not uniform with the analysis for EISCAT measurements by Litvine et al. (1998). They found that the smallest amplitude of the daily variation takes place in winter and the minimum of winter shifts to $15 \mathrm{LT}$ in the afternoon. The difference between the two sites may be caused by the latitudinal variations suggested by Bilitza (1990a). 
Table 1. Chemical reactions and rates included in the ionospheric model. $T_{\text {eff }}=\left(m_{\mathrm{i}} T_{\mathrm{n}}+m_{\mathrm{n}} T_{\mathrm{i}}\right) /\left(m_{\mathrm{i}}+m_{\mathrm{n}}\right)+0.329 E^{2}$, where $E$ is the electric field perpendicular to the geomagnetic field in $\mathrm{mV} / \mathrm{m}$.

\begin{tabular}{|c|c|c|}
\hline Reaction & Rate Coefficient, $\mathbf{m}^{3} \mathbf{s}^{-1}$, or Rate, $\mathbf{s}^{-1}$ & Reference \\
\hline & $\begin{array}{l}k_{10}=1.533 \times 10^{-18}-5.92 \times 10^{-19}\left(T_{\text {eff }} / 300\right) \\
+8.60 \times 10^{-20}\left(T_{\text {eff }} / 300\right)^{2}\left(300 \mathrm{~K} \leq T_{\text {eff }} \leq 1700 \mathrm{~K}\right)\end{array}$ & \multirow{3}{*}{ St. Maurice and Torr (1978) } \\
\hline \multirow[t]{2}{*}{$\mathrm{O}^{+}\left({ }^{4} \mathrm{~S}\right)+\mathrm{N}_{2}(v=0) \rightarrow \mathrm{NO}^{+}+\mathrm{N}$} & & \\
\hline & $\begin{array}{l}k_{10}=2.73 \times 10^{-18}-1.155 \times 10^{-18}\left(T_{\text {eff }} / 300\right) \\
+1.483 \times 10^{-19}\left(T_{\text {eff }} / 300\right)^{2}\left(1700 \mathrm{~K}<T_{\text {eff }}<6000 \mathrm{~K}\right)\end{array}$ & \\
\hline $\mathrm{O}^{+}\left({ }^{4} \mathrm{~S}\right)+\mathrm{N}_{2}(v) \rightarrow \mathrm{NO}^{+}+\mathrm{N}$ & $\begin{array}{l}k_{1}=\sum_{v=1}^{5} \mathrm{~N}_{2}(v) k_{1 v} / \mathrm{N}_{2} \\
k_{11}=k_{10} ; k_{12}=38 k_{10} ; k_{13}=85 k_{10} ; k_{14}=220 k_{10} ; k_{15}=270 k_{10}\end{array}$ & Pavlov et al. (1999) \\
\hline $\mathrm{O}^{+}\left({ }^{4} \mathrm{~S}\right)+\mathrm{O}_{2}(v) \rightarrow \mathrm{O}_{2}^{+}+\mathrm{O}$ & $k_{2}=1.7 \times 10^{-17}\left(300 / T_{\mathrm{n}}\right)^{0.77}+8.54 \times 10^{-17} \times \exp \left(-3467 / T_{\mathrm{n}}\right)$ & Hierl et al. (1997) \\
\hline $\mathrm{O}^{+}\left({ }^{2} \mathrm{D}\right)+\mathrm{N}_{2} \rightarrow \mathrm{N}_{2}^{+}+\mathrm{O}$ & $k_{3}=1.5 \times 10^{-16}\left(T_{\mathrm{eff}} / 300\right)^{0.5}$ & Li et al. (1997), Pavlov (2003) \\
\hline $\mathrm{O}^{+}\left({ }^{2} \mathrm{D}\right)+\mathrm{O}_{2} \rightarrow \mathrm{O}_{2}^{+}+\mathrm{O}$ & $k_{4}=1.3 \times 10^{-16}\left(T_{\mathrm{eff}} / 300\right)^{0.5}$ & Pavlov (2003) \\
\hline $\mathrm{O}^{+}\left({ }^{2} \mathrm{D}\right)+\mathrm{O} \rightarrow \mathrm{O}^{+}\left({ }^{4} \mathrm{~S}\right)+\mathrm{O}$ & $k_{5}=1.0 \times 10^{-16}$ & Fox and Dalgarno (1985) \\
\hline $\mathrm{O}^{+}\left({ }^{2} \mathrm{D}\right)+\mathrm{e} \rightarrow \mathrm{O}^{+}\left({ }^{4} \mathrm{~S}\right)+\mathrm{e}$ & $k_{6}=4.0 \times 10^{-14}\left(300 / T_{\mathrm{e}}\right)^{0.5}$ & $\begin{array}{l}\text { McLaughlin and Bell (1998), } \\
\text { Pavlov (2003) }\end{array}$ \\
\hline $\mathrm{O}^{+}\left({ }^{2} \mathrm{P}\right)+\mathrm{N}_{2} \rightarrow \mathrm{N}_{2}^{+}+\mathrm{O}$ & $k_{7}=2.0 \times 10^{-16}\left(T_{\mathrm{eff}} / 300\right)^{0.5}$ & Li et al. (1997), Pavlov (2003) \\
\hline $\mathrm{O}^{+}\left({ }^{2} \mathrm{P}\right)+\mathrm{N}_{2} \rightarrow \mathrm{N}^{+}+\mathrm{NO}$ & $k_{8}=1.0 \times 10^{-17}$ & Rees (1989) \\
\hline $\mathrm{O}^{+}\left({ }^{2} \mathrm{P}\right)+\mathrm{O} \rightarrow \mathrm{O}^{+}\left({ }^{4} \mathrm{~S}\right)+\mathrm{O}$ & $\mathrm{k}_{9}=4.0 \times 10^{-16}$ & Chang et al. (1993) \\
\hline $\mathrm{O}^{+}\left({ }^{2} \mathrm{P}\right)+\mathrm{e} \rightarrow \mathrm{O}^{+}\left({ }^{4} \mathrm{~S}\right)+\mathrm{e}$ & $k_{10}=2.5 \times 10^{-14}\left(300 / T_{\mathrm{e}}\right)^{0.5}$ & $\begin{array}{l}\text { McLaughlin and Bell (1998), } \\
\text { Pavlov (2003) }\end{array}$ \\
\hline $\mathrm{O}^{+}\left({ }^{2} \mathrm{P}\right)+\mathrm{e} \rightarrow \mathrm{O}^{+}\left({ }^{2} \mathrm{D}\right)+\mathrm{e}$ & $k_{11}=7.0 \times 10^{-14}\left(300 / T_{\mathrm{e}}\right)^{0.5}$ & $\begin{array}{l}\text { McLaughlin and Bell (1998), } \\
\text { Pavlov (2003) }\end{array}$ \\
\hline $\mathrm{O}^{+}\left({ }^{2} \mathrm{P}\right) \rightarrow \mathrm{O}^{+}\left({ }^{4} \mathrm{~S}\right)+h v$ & $A_{1}=0.0833 \mathrm{~s}^{-1}$ & Kaufman and Sugar (1986) \\
\hline $\mathrm{O}^{+}\left({ }^{2} \mathrm{P}\right) \rightarrow \mathrm{O}^{+}\left({ }^{2} \mathrm{D}\right)+h v$ & $A_{2}=0.277 \mathrm{~s}^{-1}$ & Kaufman and Sugar (1986) \\
\hline $\mathrm{O}_{2}^{+}+\mathrm{NO} \rightarrow \mathrm{NO}^{+}+\mathrm{O}_{2}$ & $k_{12}=4.4 \times 10^{-16}$ & Lindinger et al. (1974) \\
\hline $\mathrm{O}_{2}^{+}+\mathrm{N} \rightarrow \mathrm{NO}^{+}+\mathrm{O}$ & $k_{13}=1.2 \times 10^{-16}$ & Fehsenfeld (1977) \\
\hline $\mathrm{O}_{2}^{+}+\mathrm{e} \rightarrow \mathrm{O}+\mathrm{O}$ & $k_{14}=2.0 \times 10^{-13}\left(300 / T_{\mathrm{e}}\right)^{0.7}\left(T_{\mathrm{e}}<1200 \mathrm{~K}\right)$ & Walls and Dunn (1974) \\
\hline & $k_{14}=1.6 \times 10^{-13}\left(300 / T_{\mathrm{e}}\right)^{0.55}\left(T_{\mathrm{e}} \geq 1200 \mathrm{~K}\right)$ & Torr et al. (1976) \\
\hline $\mathrm{N}_{2}^{+}+\mathrm{O} \rightarrow \mathrm{NO}^{+}+\mathrm{N}$ & $k_{15}=1.4 \times 10^{-16}\left(300 / T_{\mathrm{i}}\right)^{0.44}$ & McFarland et al. (1974) \\
\hline $\mathrm{N}_{2}^{+}+\mathrm{O} \rightarrow \mathrm{O}^{+}\left({ }^{4} \mathrm{~S}\right)+\mathrm{N}_{2}$ & $k_{16}=9.8 \times 10^{-18}\left(300 / T_{\mathrm{i}}\right)^{0.23}$ & McFarland et al. (1974) \\
\hline $\mathrm{N}_{2}^{+}+\mathrm{O}_{2} \rightarrow \mathrm{O}_{2}^{+}+\mathrm{N}_{2}$ & $k_{17}=5.0 \times 10^{-17}\left(300 / T_{\mathrm{eff}}\right)$ & Lindinger et al. (1974) \\
\hline $\mathrm{N}_{2}^{+}+\mathrm{e} \rightarrow \mathrm{N}+\mathrm{N}$ & $k_{18}=1.75 \times 10^{-13}\left(300 / T_{\mathrm{e}}\right)^{0.3}$ & Peterson et al. (1998) \\
\hline $\mathrm{NO}^{+}+\mathrm{e} \rightarrow \mathrm{N}+\mathrm{O}$ & $k_{19}=4.2 \times 10^{-13}\left(300 / T_{\mathrm{e}}\right)^{0.85}$ & Torr et al. (1976) \\
\hline
\end{tabular}

Table 2. The extremum of LTH (maximum values $\mathrm{H}_{\max }$, and minimum values $\left.\mathrm{H}_{\min }\right)(\mathrm{km})$ of daily variation and its corresponding local time (h).

\begin{tabular}{lcccc}
\hline Season & $\mathrm{H}_{\max }$ & $\mathrm{t}_{\max }$ & $\mathrm{H}_{\min }$ & $\mathrm{t}_{\min }$ \\
\hline Spring & 224 & 1.0 & 182 & 13.0 \\
Summer & 216 & 1.0 & 188 & 16.0 \\
Autumn & 222 & 1.5 & 184 & 13.0 \\
Winter & 218 & 1.5 & 178 & 11.0 \\
\hline
\end{tabular}

Figure 3 also shows diurnal variations of the LTH predicted by IRI2000 under the same conditions. The standard IRI option (Bilitza, 1990b) values share the same tendency with another option, the D\&S model (Danilov and Simirnova, 1995), while the former is generally $20 \mathrm{~km}$ lower than the latter. In equinox, the daytime theoretical LTH is in agreement with the D\&S model, while the nighttime LTH agrees better with
Table 3. Harmonic components of fitting mean, annual and semiannual variations of LTH according to Eq. (1). Amplitudes are in $\mathrm{km}$, and phases in days.

\begin{tabular}{cccccc}
\hline Local time (hour) & $\mathrm{A}_{\mathrm{D} 0}$ & $\mathrm{~A}_{\mathrm{D} 1}$ & $\mathrm{D}_{1}$ & $\mathrm{~A}_{\mathrm{D} 2}$ & $\mathrm{D}_{2}$ \\
\hline $0: 00$ & 217 & 1 & 102 & 4 & 103 \\
$12: 00$ & 184 & 6 & 176 & 1 & 19 \\
\hline
\end{tabular}

the standard option. In summer, the theoretical altitude is close to the standard IRI option. In winter, both IRI options fail to predict the night values. The smaller day-night difference in both the IRI standard option and D\&Y model (Danilov and Yaichinikov, 1985) was reported by Zhang et al. (1996). The D\&S model, as an updated D\&Y model, now yields larger day-night differences, whereas the latest 


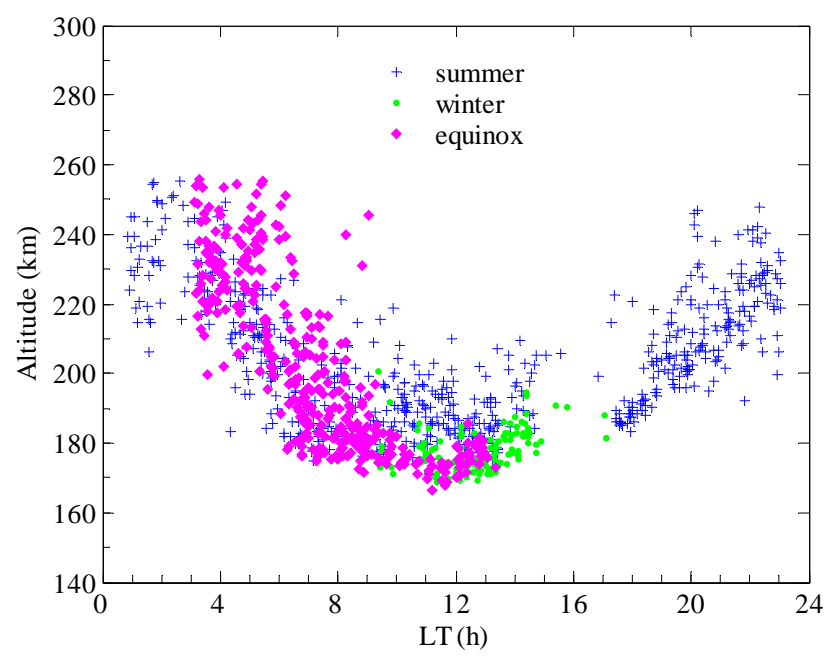

Fig. 5. The diurnal and seasonal variation of LTH derived from Atmosphere Explorer-C.

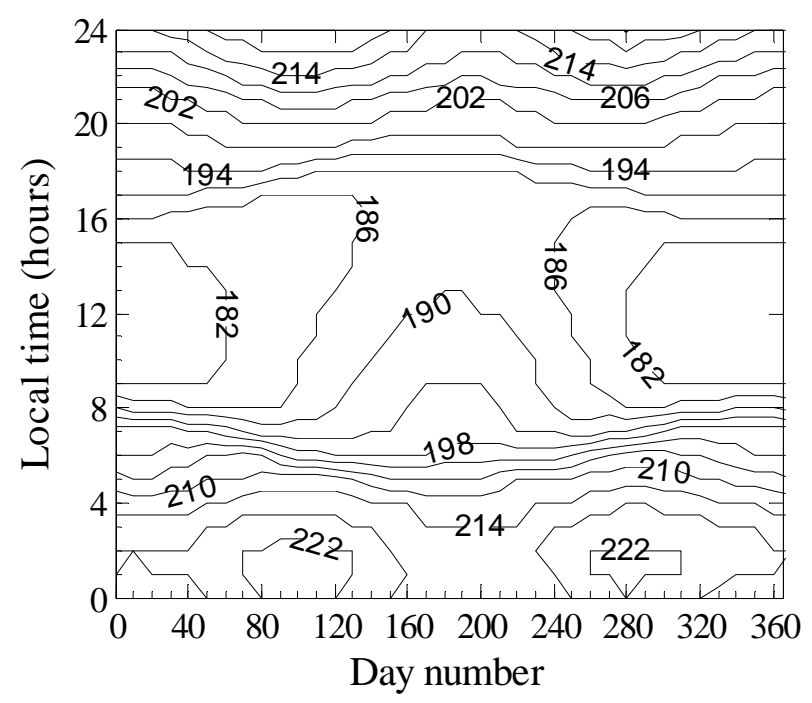

Fig. 6. Contour of the calculated LTH versus day of year and local time under $\mathrm{F} 107=100$ and $A_{p}=10$.

IRI still gives smaller day-night differences in winter. Litvine et al. (1998) had also found that the deduced LTH from EISCAT measurements showed similarities in the general trend with IRI, but still has some difference in the values and the exact behavior.

To give a more detailed pattern for the diurnal and seasonal variation, Fig. 4 displays the theoretical LTH and that from the two IRI options at two solar flux levels (F107=80 and 160). The simulated LTH shows a seasonal difference of about $10 \mathrm{~km}$, while the IRI gives a difference of more than $40 \mathrm{~km}$. During nighttime, the simulated LTH maximizes in equinox, while the IRI LTH reaches a maximum in summer. In general, both IRI options give an LTH too large in summer, but too small in winter. The simulated solar flux effect on LTH is also different from that of the IRI model, which will be discussed in the next section.
The altitude profiles of ion composition derived from AEC data in 1974 when F107 was about 80 are also used to obtain the LTH, as shown in Fig. 5 for comparisons with the model values in the left panels of Fig. 4. The simulated LTH agrees with AE-C measurements in many respects: The LTH has larger values at night than during daytime. During daytime, the LTH is highest in summer, while at night the values in equinox are larger than in summer. The seasonal difference is less than $10 \mathrm{~km}$, which is much less than what IRI predicted. In addition, the diurnal maximum occurs at $\sim 01$ LT in summer. Unfortunately, other important respects, such as the dependence of solar activity and magnetic activity, can not be investigated due to the limited observations.

\subsection{Annual and semiannual variation}

The simulated LTH exhibits different annual and semiannual variations at different local times as seen in Fig. 6. The LTH presents a dominant semiannual variation between $20 \sim 05$ LT, whereas it shows pronounced annual variations at other times. We can expect that the atmospheric parameters (neutral composition, neutral winds, etc.) contribute to this behavior. To investigate annual and semiannual variations in LTH, we express LTH at a given local time as three terms, which represent the average, annual and semiannual components, respectively:

$$
\begin{aligned}
& \mathrm{LTH}(d, \mathrm{LT})=A_{D 0}+A_{D 1} \cos \frac{2 \pi}{365}\left(d-D_{1}\right) \\
& +A_{D 2} \cos \frac{4 \pi}{365}\left(d-D_{2}\right),
\end{aligned}
$$

where LT is local time, $d$ is the day number of year, $A_{D 0}$ represents the average value, $A_{D 1}, A_{D 2}$ are the annual and semiannual amplitudes of LTH, and $D_{1}, D_{2}$ are the corresponding phase to those components, in units of days.

Table 3 gives the mean value, annual and semiannual amplitudes of LTH and the phase for two given local times. A dominant semiannual variation exhibits at midnight $A_{D 1}=1 \mathrm{~km}$ and $A_{D 2}=4 \mathrm{~km}$, and a dominant annual variation at $12 \mathrm{LT}$ with $A_{D 1}=6 \mathrm{~km}$, and $A_{D 2}=1 \mathrm{~km}$. In all, the annual and semiannual amplitudes are much smaller compared to the mean value $A_{D 0}$, and we can also conclude that the seasonal variation of LTH is quite less than the diurnal variation, as discussed previously. Existed empirical models, however, tend to predict larger seasonal variations. The Oliver's model presents an annual amplitude of $16.8 \mathrm{~km}$ and a semiannual amplitude of $9.4 \mathrm{~km}$ regardless of local time (Bilitza, 1990a). The standard IRI gives the similar variation to the Oliver's model with an averaged annual amplitude of $19.5 \mathrm{~km}$ and semiannual amplitude of $7.5 \mathrm{~km}$. And the D\&S model produces an almost identical amplitude $(\sim 10 \mathrm{~km})$ of the annual and semiannual variation of the transition height.

\subsection{Solar activity dependence}

Model calculations were made for various solar flux F107 values in order to simulate the solar activity dependence. 

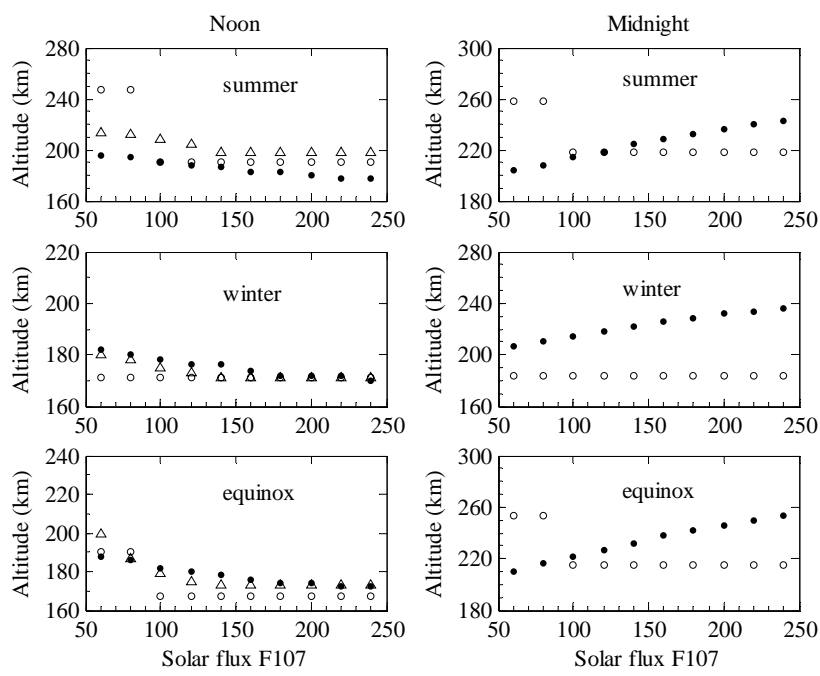

- Simulation

D\&S model

○ Standard IRI

Fig. 7. Solar activity variation of LTH at noon (left panels) and midnight (right panels) for various seasons under $A_{p}=10$. The detail can be seen in the text.

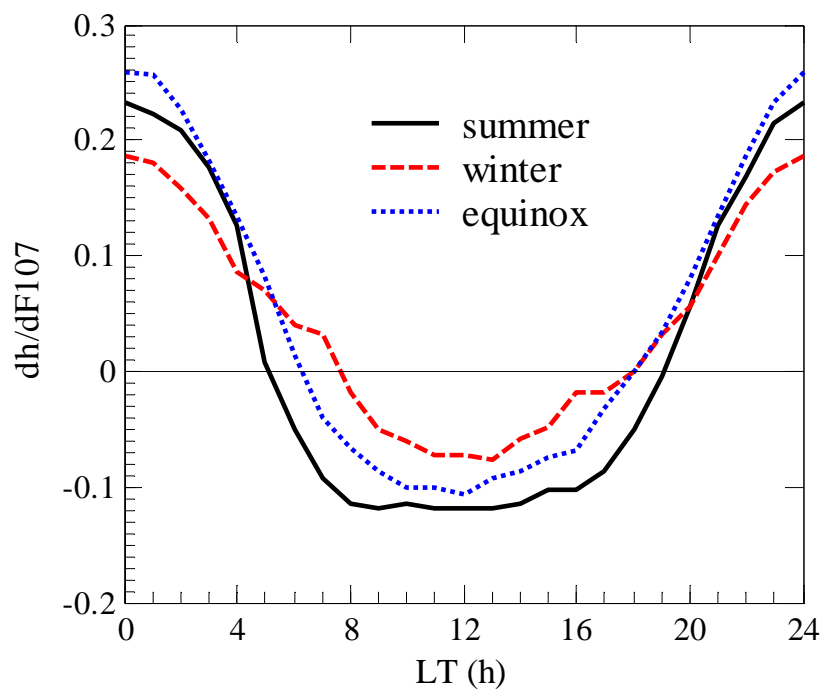

Fig. 8. Variations of the gradient $d \mathrm{~h} / d \mathrm{~F} 107$, which is the slope of a linear regression of transition height LTH to solar activity F107 values at equinox, summer and winter.

Figure 7 shows variations of the calculated LTH and IRI values with the solar flux for noon and midnight under $A_{p}=10$. During daytime, the calculated LTH decreases with the solar flux and an almost linear decrease can also be seen when F107<200; a saturation of slow decrease can be seen when F107>200. At night, the calculated LTH increases with F107, and there is a good linear relationship between the simulated LTH and F107. In the D\&S model, the LTH decreases with F107 when F107<140 during daytime and the slopes of decrease are larger than the simulated ones, while the altitude does not vary (saturation effect) for F107> 140. It should be noted that there is no data in constructing the D\&S model for the midnight sector (the zenith angle above $90^{\circ}$ ), especially in winter and equinoxes, therefore, we do not show the corresponding D\&S model values during nighttime in Fig. 7 (right-hand panels). In standard IRI, the LTH presents abrupt changes with solar flux in summer and equinox. In winter, the LTH does not vary with F107. During daytime, the IRI model gives too large values in summer when F107 $<100$, which can be observed in Fig. 4 and also have been revealed by Zhang et al. (1996). At night, because the standard IRI values show an opposite tendency to the simulated ones in summer and equinox, the values are larger than simulation when F107<100 and smaller when F107>100.

As discussed above, the solar activity dependence of LTH varies with local time. To further understand the diurnal variations of the relationship between the simulated LTH and F107, we compute and present the gradient $d(\mathrm{LTH}) / d(\mathrm{~F} 107)$ by a linear regression against local time shown in Fig. 8. We only use simulated data for F107 lower than 200 to compute the slope, because the saturation effect exists during daytime when F107>200. Results show the negative and positive slopes during daytime and nighttime, respectively. As a result, the day-night difference of LTH significantly increases with solar activity. The maximum magnitude of the slopes is about $0.1 \mathrm{~km}$ per F107 unit during daytime and around $0.2 \mathrm{~km}$ per F107 unit during nighttime. In addition, the transition time of the slope (reverse from positive to negative, or vice versa) is 06 LT and 19 LT in summer, 09 LT and $18 \mathrm{LT}$ in winter, $08 \mathrm{LT}$ and $19 \mathrm{LT}$ in equinox. It is obvious that the duration of the decrease in LTH versus solar flux (negative slope) is longest (06-19LT) in summer and shortest (09-18 LT) in winter.

\subsection{Magnetic activity dependence}

The simulated data allow us to analyze the effect of magnetic activity. The main feature is that the LTH generally increases with $A_{p}$ (Fig. 9). The amount of increase has no obvious seasonal variations. The LTH increases about $32 \mathrm{~km}$ at noon and $34 \mathrm{~km}$ at midnight when $A_{p}$ increases from 10 to 210 . The slope $d(\mathrm{LTH}) / d\left(A_{p}\right)$ is near $0.1406 \mathrm{~km}$ and $0.1736 \mathrm{~km}$ at noon and midnight, respectively, which is obtained with a linear regression. Figure 10 shows the deviation of the simulated LTH at certain $A_{p}$ from that at $A_{p}=10$ to represent the effect of magnetic activity. The mean slope of the linear fit is $0.1455 \mathrm{~km}$ per $A_{p}$ unit. Our results agree with those of Lathuillere and Pibaret (1992), which found that the amplitude of the magnetic activity variation of the LTH for $K_{p}$ ranging from 0 to $4^{+}$is about $10 \mathrm{~km}$. Litvin et al. (2000) have analyzed the ISR data over Millstone Hill and deduced the LTH from the measurements during 5-11 June 1991, a storm period. They also revealed that the LTH increased with magnetic activity. However, their slope is somewhat larger than our simulated result. 
Table 4. Harmonic components of the daily variation of LTH shown in Fig. 3. Amplitudes are in km, and phases in hours.

\begin{tabular}{lccccccc}
\hline Season & $\mathrm{A}_{0}$ & $\mathrm{~A}_{24}$ & $\mathrm{t}_{24}$ & $\mathrm{~A}_{12}$ & $\mathrm{t}_{12}$ & $\mathrm{~A}_{8}$ & $\mathrm{t}_{8}$ \\
\hline Summer & 199.3 & 13.4 & 1.51 & 3.5 & 0.70 & 1.0 & 3.49 \\
Equinox & 199.1 & 21.4 & 0.96 & 3.7 & 1.82 & 1.5 & 3.90 \\
Winter & 196.4 & 18.7 & 1.15 & 3.7 & 3.50 & 0.5 & 0.96 \\
\hline
\end{tabular}

Table 5. Harmonic components of the slope $d(\mathrm{LTH}) / d(\mathrm{~F} 107)$ shown in Fig. 8.

\begin{tabular}{lccccccc}
\hline Season & $\mathrm{C}_{0}$ & $\mathrm{C}_{24}$ & $\phi_{24}$ & $\mathrm{C}_{12}$ & $\phi_{12}$ & $\mathrm{C}_{8}$ & $\phi_{8}$ \\
\hline Summer & 0.010 & 0.179 & 0.187 & 0.055 & 0.534 & 0.008 & 2.985 \\
Equinox & 0.044 & 0.172 & 0.163 & 0.036 & 0.477 & 0.004 & -0.286 \\
Winter & 0.037 & 0.122 & 0.481 & 0.017 & 0.689 & 0.013 & -0.517 \\
\hline
\end{tabular}

\subsection{An empirical model}

The simulated LTH is fitted using the following equation

$$
\begin{aligned}
& \mathrm{LTH}(t)=A_{0}+\sum_{n=1}^{3} A_{24 / n} \cos \left(2 \pi \frac{t-t_{24 / n}}{24 / n}\right) \\
& \quad+\left[C_{0}+\sum_{n=1}^{3} C_{24 / n} \cos \left(2 \pi \frac{t-\phi_{24 / n}}{24 / n}\right)\right](\mathrm{F} 107-100) \\
& \quad+d\left(A_{p}-10\right),
\end{aligned}
$$

where the mean value $A_{0}$ and amplitude $A_{24 / n}$ and phase $t_{24 / n}$ are used to fit the time series for F107=100 and $A_{p}=10$ shown in Fig. 3; they are given in Table 4 . The mean value $C_{0}$, amplitude $C_{24 / n}$ and phase $\phi_{24 / n}$ are used to fit the slope of F107 shown in Fig. 8; these coefficients are given in Table 5 . And we take a mean slope $d=0.1455 \mathrm{~km}$ to include the magnetic activity effect (Fig. 10). Linear interpolation is performed to obtain the coefficients for any given season, solar activity or geomagnetic activity condition.

The LTH model, combined with the numerical results for the width $d z$ of the transition (defined as the altitude range between $10 \%$ and $90 \%$ of the $\mathrm{O}^{+} / \mathrm{Ne}$ ratio), to be undertaken in a further study, can be used to improve the future IRI ion composition and provide an ion composition model for the ISR (e.g. Millstone Hill ISR) data processing.

\section{Discussion}

The variation of the lower transition height (LTH) is largely controlled by changes in the solar radiation and the background neutral atmosphere. The day-night difference of LTH is mainly caused by changes of solar zenith angle and the ratio of atomic to molecular density, namely $[\mathrm{O}] /\left[\mathrm{N}_{2}\right]$ (Litvine et al., 1998). In addition, equatorward neutral winds may partly contribute to larger values of LTH at night (Zhang et
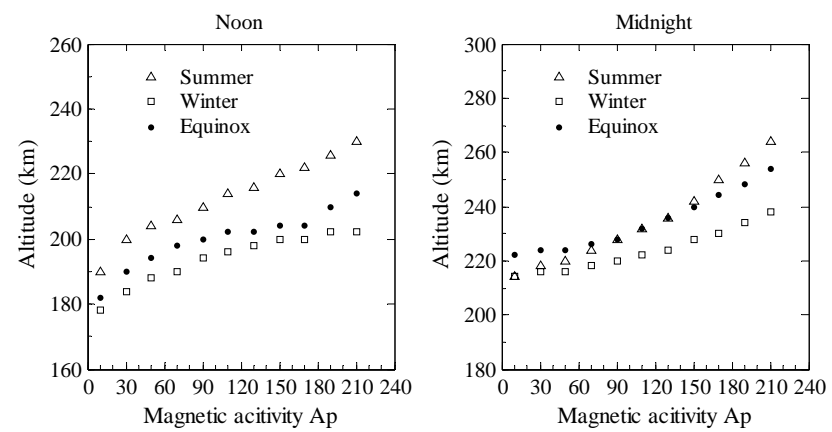

Fig. 9. Magnetic activity variation of LTH at noon (left panels) and midnight (right panels) for various seasons under F107=100.

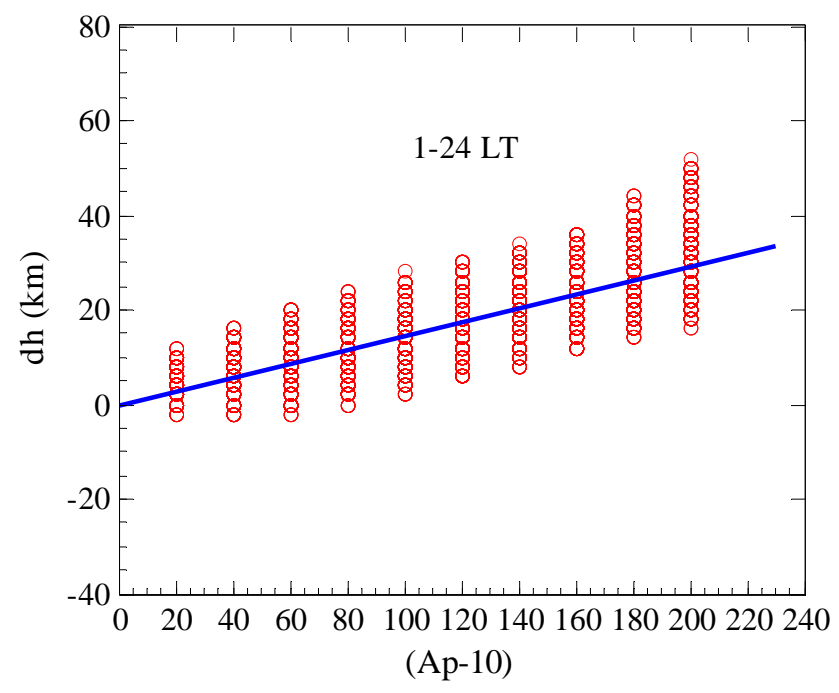

Fig. 10. Mass plot of the differences $d$ h (open circles) between the calculated LTH at certain $A_{p}$ and at $A_{p}=10$ for various seasons and all local times (1-24LT) as a function of magnetic activity. The solid line is the results of a linear regression.

al., 1996). Seasonal changes may also be partly due to seasonal variation of the $[\mathrm{O}] /\left[\mathrm{N}_{2}\right]$ ratio. In summer, smaller $[\mathrm{O}] /\left[\mathrm{N}_{2}\right]$ ratio results in larger LTH than in winter (Fig. 7 of Litvine et al., 1998). The significant solar activity dependence of LTH is expected to be associated with changes in neutral winds and the neutral composition. As solar activity increases, an increase in density of atomic oxygen and molecular density results in the increase of LTH at nighttime (Zhang et al., 1996), while the increased solar ionization flux accompanying the change in the neutral composition results in the decrease of LTH during daytime (Oliver, 1979). Furthermore, the magnetic activity dependence of LTH with a mean slope of about $0.1455 \mathrm{~km}$ per $A_{p}$ unit, seems to be linked to the decrease in the $[\mathrm{O}] /\left[\mathrm{N}_{2}\right]$ ratio as a result of high magnetic activity (Oliver, 1979; Lathuillere and Pibaret, 1992, and also references therein).

In general, theoretical modeling results of the ionosphere depend on model inputs. However, it should be kept in mind that our calculations are carried out for the American zone 
(Millstone Hill), where we expect a high accuracy in empirical models such as MSIS and HWM, which have taken into account rich observational data from this area. The AE-C data of ion composition also confirmed our simulations.

\section{Conclusion}

In this study, the diurnal, seasonal, annual and semiannual, solar activity and magnetic activity variations of the ionospheric lower transition height (LTH) over mid-latitude are investigated. Also, the AE-C data of ion composition are used for validating our analysis. Mainly results can be summarized as follows:

1. The calculated LTH reaches its diurnal minimum at 11 13 LT, and maximum after midnight (about $01 \sim 02$ LT). The local time asymmetry becomes more evident in summer. In addition, our simulation indicates a large day-night difference of LTH in winter, which, however, tends to be small in the latest IRI model.

2. The simulated LTH presents a dominant semiannual variation at night, whereas it shows a pronounced annual variation by day.

3. The calculated LTH increases with increasing solar activity at night and decreases by day, while the standard IRI values show an opposite tendency at night in summer and equinox.

4. Both daytime and nighttime LTHs tend to increase with geomagnetic activity.

5. The diurnal variation of LTH is found to be more than $20 \mathrm{~km}$, and is much larger than the seasonal variation (less than $10 \mathrm{~km}$ ) under $\mathrm{F} 107=100$ and $A_{p}=10$. The day-night difference of LTH significantly increases with solar activity. Therefore, the diurnal and solar activity variations of LTH are more pronounced than its seasonal and magnetic activity variations.

Acknowledgements. Special thanks would be given to J. E. Titheridge for providing the code of the empirical model of NO density and A. V. Pavlov for providing us with the subroutine of the steady-state analytical calculation of the vibrational temperature. This research was supported by National Natural Science Foundation of China $(40274054,40134020)$ and National Important Basic Research Project (G2000078407).

Topical Editor M. Lester thanks A. Danilov and another referee for their help in evaluating this paper.

\section{References}

Bilitza, D.: International reference ionosphere 1990, NSSDC/WDC-A-R\&S, 90-92, 1990a.

Bilitza, D.: Empirical modeling of ion composition in the middle and topside ionosphere, Adv. Space Res., 10, 47-56, $1990 \mathrm{~b}$.

Bilitza, D.: The use of transition height for the representation of the ion composition, Adv. Space Res., 11, 183-186, 1991.
Bilitza, D.: International reference ionosphere 2000, Radio Sci., 36, 261-275, 2001.

Cabrit, B. and Kofman, W.: Ionospheric composition measurement by EISCAT using a global fit procedure, Ann. Geophys., 14, 1496-1505, 1996.

Chang, T., Torr, D. G., Richards, P. G., and Solomon, S. C.: Reevaluation of the $\mathrm{O}^{+}\left({ }^{2} \mathrm{P}\right)$ reaction rate coefficients from Atmosphere Explorer C observations, J. Geophys. Res., 98, 15 589-15 597, 1993.

Danilov, A. D. and Yaichinikov, A. P.: A new model of the ion composition at 75 to $1000 \mathrm{~km}$ for IRI, Adv. Space Res., 5, 7579, 1985.

Danilov, A. D. and Simirnova, N. V.: Improving the 75-300 km ion composition model of the IRI, Adv. Space Res., 15, 171-177, 1995.

Fehsenfeld, F. C.: The reaction of $\mathrm{O}_{2}^{+}$with atomic nitrogen and $\mathrm{NO}^{+} \cdot \mathrm{H}_{2} \mathrm{O}$ and $\mathrm{NO}_{2}^{+}$with atomic oxygen, Planet. Space. Sci., 25, 195-196, 1977.

Fox, J. L. and Dalgarno, A.: The vibrational distribution of $\mathrm{N}_{2}^{+}$ in the terrestrial ionosphere, J. Geophys. Res., 90, 7557-7567, 1985.

Hedin, A. E., Fleming, E. L., Manson, A. H. et al.: Empirical wind model for the upper, middle and lower atmosphere, J. Atmos. Terr. Phys., 58, 1421-1447, 1996.

Hierl, P. M., Dotan, I., Seeley, J. V., Van Doren, J. M., Morris, R. A., and Viggiano, A. A.: Rate constants for the reactions of $\mathrm{O}^{+}$ with $\mathrm{N}_{2}$ and $\mathrm{O}_{2}$ as a function of temperature $(300-1800 \mathrm{~K})$, J. Chem. Phys., 106, 3540-3544, 1997.

Huba, J. D., Joyce, G., and Fedder, J. A.: Sami2 is another model of the ionosphere (SAMI2): A new low latitude ionospheric model, J. Geophys. Res., 105, 23 035-23 053, 2000.

Hoegy, W. R., Grebowsky, J. M., and Brance, L. H.: Ionospheric ion composition from satellite measurements made during 19701980: altitude profiles, Adv. Space Res., 11, 173-182, 1991.

Hoffman, J. H., Hanson, W. B., Lippincott, C. R., and Ferguson, E. E.: The magnetic ion-mass spectrometer on Atmosphere Explorer, Radio Sci., 8, 315-322, 1973.

Holt, J. M., Zhang, S.-R., and Buonsanto, M. J.: Regional and local ionospheric models based on Millstone Hill incoherent scatter radar data, Geophy. Res. Lett., 29, doi:10.1029/2002GL014678, 2002.

Kaufman, V. and Sugar, J.: Forbidden lines in $n s^{2} n p^{k}$ ground configuration and nsnp excited configurations of Beryllium through Molybdenum atoms and ions, J. Phys. Chem. Ref. Data, 15, 321426, 1986.

Lathuillere, C. and Pibaret, B.: A statistical model of ion composition in the auroral lower F-region, Adv. Space Res., 12, 147-156, 1992.

Li, X., Huang, Y.-L., Flesch, G. D., and Ng, C. Y.: A stateselected study of the ion-molecule reactions $\mathrm{O}^{+}\left({ }^{4} \mathrm{~S},{ }^{2} \mathrm{D},{ }^{2} \mathrm{P}\right)+\mathrm{N}_{2}$, J. Chem. Phys., 106, 1373-1381, 1997.

Lindinger, W., Fehsenfeld, F. C., Schmeltekopf, A. L., and Ferguson, E. E.: Temperature dependence of some ionospheric ionneutral reactions from 300-900 K, J. Geophys. Res., 79, 47534756, 1974.

Litvin, A., Oliver, W. L., Picone, J. M., and Buonsanto, M. J.: The upper atmosphere during June 5-11, 1991, J. Geophys. Res., 105, 12 789-12 796, 2000.

Litvine, A., Kofman, W., and Cabrit, B.: Ion composition measurement and modeling at altitude from 140 to $350 \mathrm{~km}$ using EISCAT measurements, Ann. Geophys., 16, 1159-1168, 1998. 
McFarland, M., Albritton, D. L., Fehsenfeld, F. C., Ferguson, E. E., and Schmeltekopf, A. L.: Energy dependence and branching ration of the $\mathrm{N}_{2}^{+}+\mathrm{O}$ reaction, J. Geophys. Res., 79, 2925-2926, 1974.

McLaughlin, B. M. and Bell, K. L.: Electron impact excitation of the fine-structure levels $\left(1 \mathrm{~s}^{2} 2 \mathrm{~s}^{2} 2 \mathrm{p}^{34} \mathrm{~S}_{3 / 2}^{0},{ }^{2} \mathrm{D}_{5 / 2}^{0}, 3 / 2,{ }^{2} \mathrm{P}_{3 / 2}^{0}, 1 / 2\right)$ of singly ionized atomic oxygen, J. Phys. B: At. Mol. Opt. Phys., 31, 4317-4329, 1998.

Oliver, W. L.: Models of F1-region ion composition variations, J. Atmos. Terr. Phys., 37, 1065-1076, 1975.

Oliver, W. L.: Incoherent scatter radar studies of daytime middle thermosphere, Ann. Geophys., 35, 121-139, 1979.

Pavlov, A. V. and Buonsanto, M. J.: Using steady-state vibrational temperatures to model effects of $\mathrm{N}_{2} *$ on calculations of electron densities, J. Geophys. Res., 101, 26941-26945, 1996.

Pavlov, A. V. and Buonsanto, M. J.: Anomalous electron density events in the quiet summer ionosphere at solar minimum over Millstone Hill, Ann. Geophys., 16, 460-469, 1998.

Pavlov, A. V., Buonsanto, M. J., Schlesier, A. C., and Richards, P. G.: Comparison of models and data at Millstone Hill during the 5-11 June 1991 storm, J. Atmos. Solar-Terr. Phys., 61, 263-279, 1999.

Pavlov, A. V. and Foster, J. C.: Model/data comparison of F-region ionospheric perturbation over Millstone Hill during the severe geomagnetic storm of July 15-16, 2000, J. Geophys. Res., 106, 29 051-29 069, 2001.

Pavlov, A. V.: New method in computer simulations of electron and ion densities and temperatures in the plasmasphere and lowlatitude ionosphere, Ann. Geophys., 21, 1601-1628, 2003.

Peterson, J. R., Padellec, A. L., Danared, H., Dunn, G. H., Larsson, M., Larson, A., Peverall, P., Stromholm, C., Rosen, S., Ugglas, M., and Van der Zande, W. J.: Dissociative recombination and excitation of $\mathrm{N}_{2}^{+}$: cross sections and product branching ration, J. Chem. Phys., 108, 1978-1988, 1998.

Picone, J. M., Hedin, A. E., Drob, D. P., and Aikin, A. C.: NRLMSISE-00 empirical model of the atmosphere: Statistical comparisons and scientific issues, J. Geophys. Res., 107, 1468, doi:10.1029/2002JA009430, 2002.
Rees, M. H.: Physics and Chemistry of the Upper Atmosphere, Cambridge Univ. Press, Cambridge, 125-126, 1989.

Richards, P. G., Fennelly, J. A., and Torr, D. G.: EUVAC: A solar EUV flux model for aeronomic calculations, J. Geophys. Res., 99, 8981-8992, 1994.

Schlesier, A. C. and Buonsanto, M. J.: The Millstone Hill ionospheric model and its application to the May 26-27, 1990, ionospheric storm, J. Geophys. Res., 104, 22 453-22 468, 1999.

Schmeltekopf, A. L., Ferguson, E. E., and Fehsenfeld, F. C.: Afterglow studies of the reactions $\mathrm{He}^{+}, \mathrm{He}\left(2^{3} \mathrm{~S}\right)$, and $\mathrm{O}^{+}$with vibrationally excited $\mathrm{N}_{2}$, J. Chem. Phys., 48, 2966-2973, 1968.

Strobel, D. F., Young, T. R., Meier, R. R., Coffey, T. P., and Ali, A. W.: The nighttime ionosphere: E-region and lower F-region, J. Geophys. Res., 79, 3171-3178, 1974.

St.-Maurice, J.-P. and Torr, D. G.: Nonthermal rate coefficients in the ionosphere: The reactions of $\mathrm{O}^{+}$with $\mathrm{N}_{2}, \mathrm{O}_{2}$ and NO, J. Geophys. Res., 83, 969-977, 1978.

Titheridge, J. E.: Direct allowance for the effect of photoelectrons in ionospheric modeling, J. Geophys. Res., 101, 357-369, 1996.

Titheridge, J. E.: Model results for the ionospheric E-region: solar and seasonal changes, Ann. Geophys., 15, 63-78, 1997.

Torr, D. G., Torr, M. R., Walker, J. C. G., Nier, A. O., Brace, L. H., and Briton, H. C.: Recombination of the $\mathrm{O}_{2}^{+}$in the ionosphere, J. Geophys. Res., 81, 5578-5580, 1976.

Waldteufel, P.: Combined incoherent-scatter F1-region observations, J. Geophys. Res., 76, 6995-6999, 1971.

Walls, F. L. and Dunn, G. H.: Measurement of total cross sections for electron recombination with $\mathrm{NO}^{+}$and $\mathrm{O}_{2}^{+}$using ion storage techniques, J. Geophys. Res., 79, 1911-1915, 1974.

Zhang, S.-R., Zhang, M.-L., Radicella, S. M., Huang, X.-Y., and Bilitza, D.: A comparison of the lower transition height obtained with a theoretical model and with IRI, Adv. Space Res., 18, 165173, 1996. 